\title{
INFLUÊNCIA DO CAMPO ELETROMAGNÉTICO NO REUSO DE CÉLULAS PARA A BIORREMOÇÃO DE CROMO
}

\author{
N. M. TERRA ${ }^{1}$, V. S. LOPES $^{2}$, P. P. P. FILHO ${ }^{3}$, V. L. CARDOSO ${ }^{4}$ e M. M. RESENDE ${ }^{5}$ \\ 1,2,3,4,5 Universidade Federal de Uberlândia, Departamento de Engenharia Química \\ E-mail para contato: nat.mazza@hotmail.com
}

\begin{abstract}
RESUMO - A contaminação das águas com efluentes contendo substâncias tóxicas, como metais pesados, representam um grande problema ambiental. Dentre as fontes poluidoras estão os curtumes que geram grandes volumes de efluentes, com alta carga orgânica e elevadas concentrações de cromo, sendo os tratamentos convencionais insuficientes para cumprir os padrões estabelecidos pela legislação. Neste trabalho avaliou-se a aplicação e reutilização de uma cultura mista na biorremoção do cromo VI (150mg/L), pH 6, em reator batelada com agitação mecânica de $500 \mathrm{rpm}$. O efluente foi bombeado por meio de uma tubulação imersa num campo eletromagnético a 5 e $10 \mathrm{~Hz}$ e também foi bombeado sem a aplicação de campo. A biorremoção do cromo atingiu valores acima de $95 \%$ para o primeiro teste em todas as condições analisadas, porém no reuso das células, o campo de $5 \mathrm{~Hz}$ apresentou melhores resultados, acima de $90 \%, 76 \%$ sem campo e 57\% com campo de $10 \mathrm{~Hz}$.
\end{abstract}

\section{INTRODUÇÃO}

$\mathrm{O}$ crescimento industrial em conjunto com a ausência de tratamento de efluentes eficientes e que cumpram com os limites estabelecidos pela legislação tem contribuído para sérios problemas ambientais. O cromo é um elemento introduzido no meio ambiente pelo seu uso industrial, especialmente em curtumes. O cromo é encontrado na forma de $\mathrm{Cr}$ (VI) e $\mathrm{Cr}$ (III), sendo a forma hexavalente considerada mais tóxica, devido a sua alta solubilidade e significativa mobilidade no ambiente (Hena, 2010; Yao-Xing et al., 2011).

Atualmente, a tecnologia mais comumente utilizada para o tratamento de metais pesados em águas residuais é a precipitação química. Este tratamento químico é realizado em pH baixo, e a solução é seguida de neutralização para precipitar o Cr(III) como hidróxidos (Wang e Shen, 1997, Chirwa e Wang, 1997; Patterson 1985; Chen e Hao 1998). Porém, este método não é completamente satisfatório por causa da grande quantidade de produtos residuais secundários devido aos vários reagentes usados nos processos mencionados.

A biossorção que é a captação passiva de íons metálicos através de materiais biológicos, e é uma tecnologia que vem emergindo na remoção de íons metálicos de soluções contaminadas é de grande importância, uma vez que apresenta baixo custo de operação, alta eficiência e possível regeneração do biossorvente (Seolatto et al., 2009). Destaca-se como uma grande alternativa para 


\section{9 a 22 de outubro de 2014 \\ Florianópolis/SC}

remoção de metais, pois, quando comparada com os processos convencionais, apresenta reconhecidas vantagens como: os metais podem ser removidos da solução independentemente do grau de toxidez, os tempos de operação são pequenos quando o equilíbrio é alcançado, não produz compostos secundários com toxicidade e pode ser altamente seletiva (Ferreira et al., 2007).

Há evidências substanciais indicando que campos magnéticos estáticos de intensidade moderada são capazes de influenciar uma série de sistemas biológicos, especialmente aqueles cuja função está intimamente ligada às propriedades dos canais da membrana (Rosen, 2003). As modificações celulares e moleculares induzidas quando campo magnético interage com materiais biológicos são, no entanto, dependente da duração da exposição, de penetração do tecido, e a geração de calor, que por sua vez está relacionada com a sua intensidade e frequência. Além disso, as respostas celulares dependem não apenas da intensidade e da frequência do campo, mas também do tipo de campo (estático ou oscilatório), na forma de onda (sinusoidal, quadrada, etc), no estado biológico (Cossarizza et al., 1989; Walleczek e Liburdy, 1990) e com o tipo de células expostas.

O objetivo deste trabalho foi o de avaliar o comportamento de uma cultura mista de microorganismos na remoção do cromo hexavalente por tratamento anaeróbio de efluentes contaminados com cromo (concentração inicial de $150 \mathrm{mg} / \mathrm{L}$ ), após a aplicação de campo eletromagnético nas frequências de 5 e $10 \mathrm{~Hz}$ e também sem a aplicação de campo.

\section{METODOLOGIA UTILIZADA}

\subsection{Micro-organismos}

Na realização deste trabalho foi utilizada uma cultura mista obtida a partir do lodo da indústria de curtume AMCOA - Associação dos Manufatores de Couros e Afins do Distrito Industrial de Franca/SP, situada na cidade de Franca-SP. Esta cultura mista foi mantida no meio de cultura de composição: $\mathrm{NH}_{4} \mathrm{Cl} 1$ g.L $\mathrm{L}^{-1} ; \mathrm{K}_{2} \mathrm{HPO}_{4} 0,5$ g.L $\mathrm{L}^{-1} ; \mathrm{MgSO}_{4} .7 \mathrm{H}_{2} \mathrm{O} 0,2$ g.L $\mathrm{L}^{-1} ; \mathrm{FeSO}_{4} .7 \mathrm{H}_{2} \mathrm{O} 0,001$ g.L $\mathrm{L}^{-1}$; $\mathrm{CaCl}_{2} \cdot 2 \mathrm{H}_{2} \mathrm{O}$ 0,001 g.L. ${ }^{-1}$; Extrato de Levedura 3 g.L $\mathrm{L}^{-1} ; \mathrm{CH}_{3} \mathrm{COONa} .3 \mathrm{H}_{2} \mathrm{O} 6$ g.L $\mathrm{L}^{-1}$, com renovação do meio de cultura a cada dois dias.

\subsection{Fonte de $\mathrm{Cr}$ (VI)}

A fonte de cromo hexavalente utilizada foi o dicromato de potássio $\left(\mathrm{K}_{2} \mathrm{Cr}_{2} \mathrm{O}_{7}\right)$ P.A. marca Vetec, na proporção de $2,82 \mathrm{mg} / \mathrm{L}$ de $\mathrm{K}_{2} \mathrm{Cr}_{2} \mathrm{O}_{7}$ para obter $1 \mathrm{mg} / \mathrm{L}$ de $\mathrm{Cr}$ (VI). Os micro-organismos foram centrifugados, ressuspensos em meio de cultura e $\mathrm{Cr}$ VI na concentração inicial de $150 \mathrm{mg} / \mathrm{L}$, pH 6 e colocados em reator batelada com agitação mecânica de $500 \mathrm{rpm}$, sendo que o efluente era bombeado por uma tubulação imersa num campo eletromagnético a 5 e $10 \mathrm{~Hz}$. O mesmo procedimento também foi adotado, porém sem o uso do campo. 


\subsection{Métodos Analíticos}

\subsubsection{Cromo total}

A concentração de cromo total foi determinada por espectrometria de absorção atômica em chama, marca Shimadzu, modelo AA-7000.

\subsubsection{Cromo VI}

Para a quantificação da concentração de cromo VI preparou-se uma curva de calibração segundo método Colorimétrico/3500-Cr B e uso do espectrofotômetro modelo Thermo Spectronic marca Genesys $10 \mathrm{UV}$, com leitura de absorbância a $540 \mathrm{~nm}$, de acordo com Standard Methods for the Examination of Water and Wastewater (APHA, 2005).

\section{RESULTADOS}

Os resultados obtidos na remoção do cromo total em função do tempo para os ensaios realizados com a aplicação do campo $(5$ e 10Hz) e sem campo estão apresentados pela Figura 1.

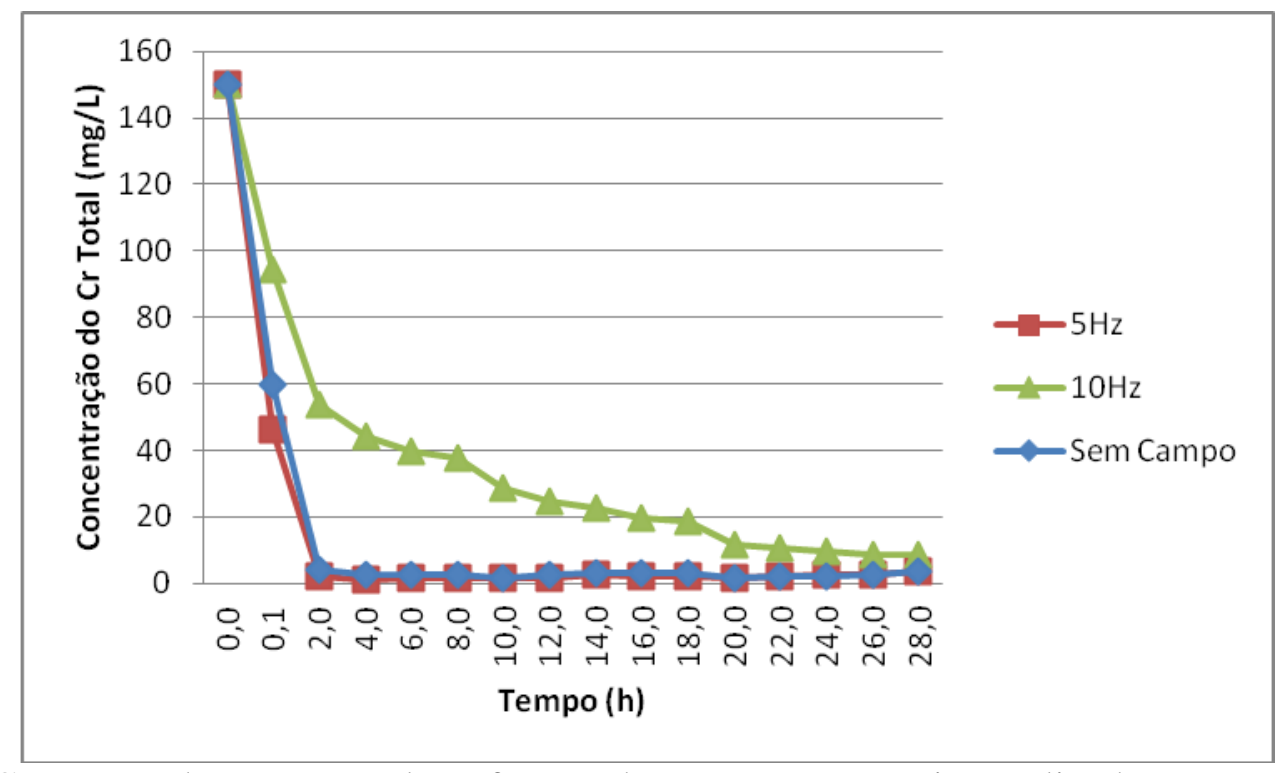

Figura 1 - Concentra do cromo total em função do tempo para ensaios realizados com aplicação de campo (5 e $10 \mathrm{~Hz})$ e sem aplicação do campo.

A cultura mista utilizada neste trabalho apresentou elevada remoção para os testes realizados, sendo que a remoção foi acima de $90 \%$ em 2 horas de experimento, tanto para o campo de $5 \mathrm{~Hz}$ quanto na ausência do campo, e em ambos os casos a estabilidade foi atinginda com 4 horas.

Para o campo de $10 \mathrm{~Hz}$ a remoção aconteceu de forma lenta e gradativa, sendo necessária 8 horas para remover $74,8 \%$ do cromo total presente no efluente, e mesmo com 28 horas de experimento, a remoção final não atingiu os mesmo patamares que das demais condições estudadas. 
Assim, a redução de cromo total aconteceu de forma mais lenta para o campo com maior intensidade.

Com a finalidade de saber em qual forma se encontra o cromo no efluente em questão, analisou-se o cromo hexavalente, Tabela 1:

Tabela 1 - Valores de remoção de Cr VI e total em porcentagem para aplicação de campo (5 e $10 \mathrm{~Hz}$ ) e sem aplicação do campo, no primeiro uso do inóculo

\begin{tabular}{|c|r|r|r|r|r|r|}
\hline \multirow{2}{*}{ Tempo (h) } & \multicolumn{2}{|c|}{$5 \mathrm{~Hz}$} & \multicolumn{2}{|c|}{$10 \mathrm{~Hz}$} & \multicolumn{2}{|c|}{ Sem campo } \\
\cline { 2 - 5 } & Cr VI & Cr total & Cr VI & Cr total & Cr VI & Cr total \\
\hline 0 & 0,00 & 0,00 & 0,00 & 0,00 & 0,00 & 0,00 \\
\hline 0,1 & 69,39 & 69,23 & 47,43 & 36,98 & 60,82 & 60,18 \\
\hline 2 & 99,92 & 98,58 & 71,76 & 64,32 & 99,59 & 97,20 \\
\hline 4 & 99,93 & 99,21 & 76,17 & 70,55 & 99,95 & 98,41 \\
\hline 6 & 99,93 & 98,94 & 79,19 & 73,50 & 99,96 & 98,18 \\
\hline 8 & 99,96 & 98,81 & 81,39 & 74,77 & 99,96 & 98,28 \\
\hline 10 & 100,00 & 98,92 & 88,69 & 81,05 & 100,00 & 98,78 \\
\hline 12 & 100,00 & 98,83 & 90,17 & 83,65 & 100,00 & 98,41 \\
\hline 14 & 100,00 & 98,25 & 91,65 & 85,06 & 100,00 & 97,85 \\
\hline 18 & 100,00 & 98,61 & 92,10 & 86,93 & 100,00 & 97,82 \\
\hline 20 & 100,00 & 98,54 & 95,19 & 87,55 & 100,00 & 98,01 \\
\hline 22 & 100,00 & 98,97 & 96,49 & 92,18 & 100,00 & 98,97 \\
\hline 26 & 100,00 & 98,48 & 96,96 & 92,85 & 100,00 & 98,68 \\
\hline 28 & 100,00 & 98,41 & 97,25 & 93,56 & 100,00 & 98,61 \\
\hline & 100,00 & 98,18 & 98,08 & 94,26 & 100,00 & 98,21 \\
\hline 16 & 100,00 & 97,62 & 98,24 & 94,32 & 100,00 & 97,65 \\
\hline
\end{tabular}

Analisando a Tabela 1, observa-se que o comportamento da remoção do cromo hexavalente foi muito semelhante a do cromo total, indicando assim que não houve alteração significativa do estado de oxidação do cromo pela cultura mista utilizada. Assim, o Cr total presente no efluente encontra-se basicamente na forma de $\mathrm{Cr}^{+6}$.

Ao fim das 28 horas de experimentos, as células utilizadas no reator foram centrifugadas e reutilizadas nas mesmas condições anteriores. $\mathrm{O}$ efluente utilizado nestes experimentos foi na concentração inicial de $150 \mathrm{mg} / \mathrm{L}$ de cromo VI. Assim, a concentração de cromo com o reuso das células está apresentada na Figura 2: 


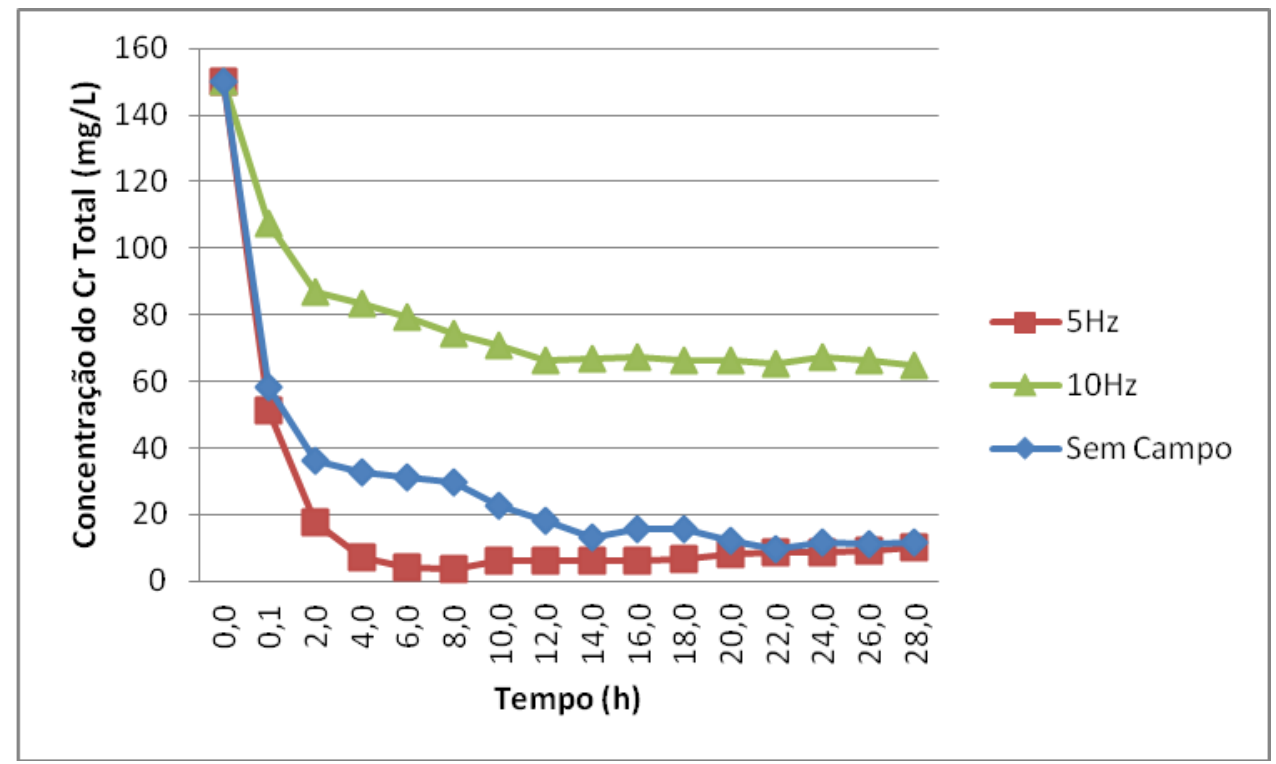

Figura 2 - Concentração do cromo total em função do tempo com as células reutilizadas.

Diferente dos resultados obtidos no primeiro uso, neste caso o campo mostrou-se influente na remoção do cromo total. Ao fazer uso da frequência de $5 \mathrm{~Hz}$ obteve-se uma remoção significativa nas primeiras 6 horas de experimento, atingindo mais de $90 \%$ de remoção, e mantendo-se estável até o final do teste. Na ausência do campo, houve uma remoção de 75,8\% em duas horas, e decaindo gradativamente e atingindo a estabilidade após 22 horas, obtendo uma remoção final de 92,2\%.

O campo de $10 \mathrm{~Hz}$ foi o que mostrou a menor remoção do cromo total, sendo de $47 \%$ com 6 horas de experimento. A remoção foi estabilizada após 12 horas, atingindo uma remoção final de $56,7 \%$, sendo a condição que apresentou a menor remoção. Tal fato, vem indicar a possível saturação das células, fator que dificulta a remoção do cromo.

Tabela 2:

Analisando novamente em qual tipo de oxidação se encontra o efluente em questão, tem-se a

Tabela 2 - Remoção do Cromo VI e total em porcentagem com reuso das células do Teste 1 para aplicação de campo (5 e 10Hz) e sem aplicação do campo

\begin{tabular}{|c|r|r|r|r|r|r|}
\hline \multirow{2}{*}{ Tempo (h) } & \multicolumn{2}{|c|}{$5 \mathrm{~Hz}$} & \multicolumn{2}{|c|}{$10 \mathrm{~Hz}$} & \multicolumn{2}{|c|}{ Sem campo } \\
\cline { 2 - 7 } & Cr VI & Cr total & Cr VI & Cr total & Cr VI & \multicolumn{1}{c|}{ Cr total } \\
\hline 0 & 0,00 & 0,00 & 0,00 & 0,00 & 0,00 & 0,00 \\
\hline 0,1 & 59,35 & 65,78 & 26,86 & 28,24 & 56,41 & 61,18 \\
\hline 2 & 90,61 & 88,36 & 46,38 & 42,21 & 72,82 & 75,76 \\
\hline 4 & 98,41 & 95,19 & 48,33 & 44,54 & 76,45 & 78,37 \\
\hline 6 & 99,99 & 97,41 & 49,88 & 47,02 & 77,76 & 79,36 \\
\hline 8 & 99,99 & 97,68 & 52,49 & 50,35 & 79,51 & 80,22 \\
\hline 10 & 99,98 & 95,97 & 56,41 & 52,73 & 90,20 & 84,93 \\
\hline
\end{tabular}




\section{9 a 22 de outubro de 2014 \\ Florianópolis/SC}

\begin{tabular}{|r|r|r|r|r|r|r|}
\hline 12 & 99,98 & 95,93 & 57,15 & 55,95 & 92,54 & 87,74 \\
\hline 14 & 99,98 & 95,89 & 57,80 & 55,35 & 93,41 & 91,12 \\
\hline 16 & 99,98 & 95,95 & 58,70 & 55,29 & 94,23 & 89,60 \\
\hline 18 & 99,98 & 95,52 & 59,43 & 55,72 & 92,27 & 89,72 \\
\hline 20 & 99,98 & 94,57 & 60,33 & 55,66 & 98,83 & 91,75 \\
\hline 22 & 99,98 & 94,32 & 61,23 & 56,51 & 99,38 & 93,67 \\
\hline 24 & 99,97 & 94,22 & 61,55 & 55,24 & 99,60 & 92,35 \\
\hline 28 & 99,97 & 93,98 & 62,45 & 55,82 & 99,63 & 92,64 \\
\hline & 99,94 & 93,13 & 62,05 & 56,67 & 99,64 & 92,23 \\
\hline
\end{tabular}

Assim como no primeiro uso das células, observa-se que o cromo do efluente tratado durante todo o experimento encontra-se basicamente na forma hexavalente.

\section{CONCLUSÕES}

A cultura mista utilizada neste trabalho foi promissora na remoção do cromo hexavalente, apresentando os melhores resultados para o campo de $5 \mathrm{~Hz}$, com reduções acima de $90 \%$, com $2 \mathrm{~h}$ de reação, para células usadas nos dois primeiros ensaios, chegando a zerar a concentração de $\mathrm{Cr}$ no primeiro uso das células ao final do tempo de experimento.

Em todos os testes, verificou-se remoções significativas, sendo notável que no reuso das células houve a saturação dos micro-organismos reutilizados, pois trabalhou-se com concentrações iniciais de $150 \mathrm{mg} / \mathrm{L}$ de cromo, valor este acima dos comumente empregado pelas industrias. A saturação foi observada principalmente para a maior frequência utilizada, de $10 \mathrm{~Hz}$, sendo a que apresentou os menores valores de remoção, e o campo de $5 \mathrm{~Hz}$ foi o que mostrou-se menos saturado, com elevadas remoções, acima de $90 \%$, mesmo com o reuso.

O reuso das células levou a saturação das mesmas com cromo, reduzindo a eficiência na remoção e comprometendo a redução do $\mathrm{Cr}^{+6} \mathrm{a} \mathrm{Cr}^{+3}$. Assim, faz-se necessário a retirada de parte das células para dar entrada a novas, visando assim estabelecer um regime no qual se tenha uma melhor eficiência na remoção.

\section{REFERÊNCIAS}

APHA, AWWA and WEF; Standart Methods for the examination of water \& wastewater, 21 st edition, 2005.

CHEN, J. M.; HAO, O. J.; Microbial Cr (VI) reduction, Crit. Rev. Environ. Sci. Technol. 28 (3), 219$251,1998$.

CHIRWA, E. M. N.; WANG, Y.; Hexavalent chromium reduction by Bacillus sp. in a packed-bed bioreactor, Environ. Sci. Technol. 31 1446-1451, 1997. 
COSSARIZZA, A.; MONTI, D.; BERSANI, F.; CANTINI, M.; CADESI, R.; SACCHI, A.; FRANCESCHI, C.; Extremely low frequency pulsed electromagnetic fields increase cell proliferation in lymphocytes from young and aged subjects. Biochemical and Biophysical Research Communication 160, 692-698, 1989.

FERREIRA, J. M. et al.; Estudo do Equilíbrio e Cinética da Biossorção do $\mathrm{Pb}^{2+}$ por Saccharomyces cerevisiae. Química Nova, vol. 30, n. 5, p. 1188-1193, 2007.

HENA, S.; Removal of chromium hexavalent ion from aqueous solutions using biopolymer chitosan coated with poly 3-methyl thiophene polymer. Journal Hazard Mater, 181:474-9, 2010.

PATTERSON, J. W.; Industrial Wastewater Treatment Technology. Butterworth Publishers, Stoneham, MA, pp., 53-393, 1985.

ROSEN, A. D.; Mechanism of action of moderate-intensity static magnetic fields on biological systems. Cellular Biochemistry Biophysics 39, 163-173, 2003.

SEOlATtO, A. A.; CÂMARA, M. M.; TAVARES, C. R.; COSSICH, E. S.; SIlVA, E. A.; Remoção de níquel(II) de soluções aquosas pela biomassa Sargassum filipendula em múltiplos ciclos de sorção-dessorção. Acta Scientiarum Technology, v. 31, n. 1, p. 57-64, 2009.

WALLECZEK, J.; LIBURDY, R.P.; Nonthermal 60-Hz sinusoidal magnetic field exposure enhances 45CaCC uptake in rat thymocytes: dependence on mitogen activation. FEBS Letters 271, 157-160, 1990.

WANG, Y.; SHEN, H.; Modeling Cr(VI) reduction by pure bacterial cultures, Water Res. 31 (4) 727-732, 1997.

YAO-XING, L.; DONG-XING, Y.; JUN-MEI, Y.; QUAN-LONG, L.; TONG, O.; Electrochemical removal of chromium from aqueous solutions using electrodes of stainless steel nets coated with single wall carbon nanotubes. Journal Hazard Mater, 186:473-80, 2011. 